\title{
EVALUATING THE SPREAD OF 10 INVASIVE WEEDS IN CHINESE NATURE RESERVES UNDER CLIMATE CHANGE SCENARIOS IN CONSIDERATION OF DIFFERENT SCALES
}

\author{
WANG, C.-J. ${ }^{1,2}-$ YIN, G.-J. ${ }^{3}-$ SONG, Z.-M. ${ }^{3}-$ WAN, J.-Z. ${ }^{*}$ \\ ${ }^{I}$ State Key Laboratory of Plateau Ecology and Agriculture, Qinghai University \\ 810016 Xining, China \\ ${ }^{2}$ College of Agriculture and Animal Husbandry, Qinghai University, 810016 Xining, China \\ ${ }^{3}$ Qinghai Forest Seedling Station, 810016 Xining, China \\ *Corresponding author \\ e-mail:wan1276@163.com
}

(Received $5^{\text {th }}$ Nov 2018; accepted $8^{\text {th }}$ Feb 2019)

\begin{abstract}
Species distribution models are powerful tools for predicting species distributions and for assessing whether particular areas are at risk from invasive weeds, but they may produce different results when different climate data scales are used in the estimate. The results of species distribution models were compared across different spatial scales, and then evaluated the spread of invasive weeds in Chinese nature reserves under several models of climate change. We used Maxent software to estimate the potential spread of 10 phylogenetically diverse alien weeds in the largest 333 Chinese nature reserves. The estimates of invasive weed spread in nature reserves were not stable against changes in spatial scale. The 2.5 arc-minute data was selected to evaluate the ability of invasive weeds to spread in Chinese nature reserves under climate change. Nature reserves with a high risk of invasive weed spread were mainly distributed in southern China. We found a significant relationship between increased invasive weed spread and low and high concentration scenarios, suggesting we should prioritize the prevention and control of invasive weeds now to lessen their impact on nature reserves in the future. It is suggested that other studies may benefit from integrating different scales into the distribution models of invasive weeds.
\end{abstract}

Keywords: ALIEN weeds, China, climate change, plant spread risk, Maxent, nature reserves, scale effect

\section{Introduction}

Species distribution models (SDMs) are powerful tools for predicting species distributions and thus they support biological conservation and risk assessment of biological invasion in nature reserves (Alagador et al., 2011; Araújo et al., 2011; Elith et al., 2011; Velásquez-Tibatá et al., 2013; Wan and Wang, 2018). These models have used climate data to assess the distributions of invasive weeds (Chejara et al., 2010; Costa et al., 2013; Sheppard, 2013; Qin et al., 2014). Because invasive weeds represent introduced plant species with generally broad physiological niches and/or some special traits and may respond quickly to changing environmental conditions (Stratonovitch et al., 2012), climate change may increase the possibilities for invasive weeds to invade nature reserves and subsequently damage the efficacy of nature reserves for conservation (Ingwell and Bosque-Pérez, 2015; Thalmann et al., 2015; Merow et al., 2017). Hence, the management of invasive weeds in nature reserves is urgent (Foxcroft et al., 2017). The use of SDMs in biological invasion gives us the new insights into the prevention and control of invasive weeds in nature reserves. 
However, there are still many technical challenges associated with the use of SDMs in the prediction of invasive weeds. Understanding the effects of input data on SDM outputs may increase the precision of the models, thereby improving their usefulness to the risk management of invasive weeds in nature reserves (Elith et al., 2011; Merow et al., 2013).

One notable challenge with SDMs is that their predictive accuracy may vary at the different scales of input data (Rahbek and Graves, 2001; Wang et al., 2012). Some studies have demonstrated that SDMs at finer scales may reduce the uncertainty of the model output (Franklin et al., 2013; Bean et al., 2014). However, a particular scale of input localities may not meet the requirements of the model due to spatial bias in the species distribution data. This would have the potential to strongly distort our view of large-scale biodiversity patterns (Beck et al., 2014). For instance, some studies have shown that databases such as Global Biodiversity Information Facility (GBIF) have a spatially biased dataset due to uneven effort of sampling, data storage and mobilization (Beck et al., 2013, 2014). These studies have found that the most robust estimates of potential species distributions use the data at coarse resolutions (Beck et al., 2013, 2014). SDMs at coarser scales may over-estimate the size of a species distribution in the present and under different climate scenarios (Bean et al., 2014; Suárez-Seoane et al., 2014). These findings suggest that selecting the appropriate spatial scale is important for researchers to accurately estimate robust distribution models (Franklin et al., 2013).

Climate change studies have found that distribution patterns and the variables that determine distribution ranges vary when different spatial scales are used (Rahbek and Graves, 2001; Wang et al., 2012; Porfirio, 2014; Wan et al., 2016). One reason for this variation may be that the scale effect may be particularly pronounced in ecologically complex situations such as climate change (Rahbek and Graves, 2001). On the other hand, as a species expands its area of distribution, the explanatory power of climate variables may also increase, while the explanatory power of habitat heterogeneity and human activities may decrease (Wang et al., 2012). Hence, spatial scale affects estimates of the potential distribution of species under climatic change and the most appropriate scale to model the species distribution must be identified. Franklin et al. (2013) proposed selecting the appropriate scale by finding the smallest bias between results from different scales. There is usually a linear relationship between SDM model estimates at fine and coarse scales (Franklin et al., 2013). This relationship suggests that SDMs need to balance data scale with distribution estimate accuracy (Metzger et al., 2005; Wan et al., 2016).

Previous studies have used different scales (from 0.5 to 10.0 arc-minutes) to model the potential species distributions in nature reserves and did not consider the effect of spatial scales (Araújo et al., 2011; Elith et al., 2011; Jiménez-Alfaro et al., 2012; Thalmann et al., 2015). Not only that, few studies used SDMs to evaluate the risk of weed spread in nature reserves by predicting the potential distributions of invasive weeds at a large spatial scale. Thus, a challenging question is to predict whether and how invasive weeds spread in nature reserves that have been established to protect threatened native species, habitats and ecosystems under future climate change (Vanderhoeven et al., 2011). Therefore, we propose a method to integrate different spatial scales into SDMs in order to assess the vulnerability of Chinese nature reserves to invasive weeds under three climate change scenarios. To address the issue of spatial scale, a simple method was developed to improve SDM estimates for nature reserves 
using data at several different spatial scales, and to identify the appropriate scale with which to model potential distributions of invasive weeds.

The main aim of our study is to evaluate the spread of 10 invasive weeds in Chinese nature reserves under climate change scenarios in consideration of different scales. For achieving this aim, we used 10 important invasive weeds in 333 Chinese nature reserves as the study cases. The Maxent software was used to model the current and future potential distributions of 10 invasive weeds across four spatial scales (grid resolution ranged from 1 to $256 \mathrm{~km}^{2}$; Crall et al., 2015) and quantified the ability of invasive weeds to spread in nature reserves. Our approach is useful to identify the appropriate data scale for SDMs and our method can be especially useful to assess the spread of invasive weeds.

\section{Materials and methods}

\section{Nature reserves in China}

In 2012 China had 2,588 nature reserves covering a total area of ca. 149 million $\mathrm{km}^{2}$ and representing ca. $14.17 \%$ of the land area (www.nre.cn). The world database of protected areas (WDPA; www.protectedplanet.net) was used to identify nature reserves (IUCN I-VI) in China with areas greater than $256 \mathrm{~km}^{2}$ and thus, covering at least one grid cell of $256 \mathrm{~km}^{2}$.

\section{Invasive plant data}

We modelled the potential spread of 10 invasive weeds including Bidens pilosa, Amaranthus spinosus, Cassia mimosoides, Conyza Canadensis, Daucus carota, Euphorbia hirta, Medicago sativa, Physalis angulate, Sonchus oleraceus and Vicia sativa in 333 nature reserves in China (Li, 1998; Xu and Qiang, 2011; Table Al in the Appendix). The species were chosen for this study according to four criteria: (1) the species had the most distribution records in China based on the study of $\mathrm{Xu}$ and Qiang (2011) and on the Chinese Virtual Herbarium (CVH; www.cvh.org.cn), (2) species occurrence records were dense enough to support a robust SDM (Phillips and Dudík, 2008), (3) species were widely distributed in China (Xu and Qiang, 2011) and (4) species have the negative impact on a variety of endangered plant species and ecosystem (Xu and Qiang, 2011). Occurrence records for the 10 invasive weeds, especially herbarium specimens or recorded sightings, were compiled from GBIF (www.gbif.org) and CVH (www.cvh.org.cn; Bird et al., 2014; Crall et al., 2015). We used descriptions of species locations in $\mathrm{CVH}$ to determine the localities within Google Earth and ArcGIS 10.2 (Bird et al., 2014; Zhang and Zhang, 2014; ESRI, 2014; Table A1). The occurrence records of 10 invasive weeds can cover the distribution range of species in China.

\section{Bioclimatic data}

The current potential distributions of invasive weeds in nature reserves were modelled using 19 bioclimatic variables available on the WorldClim database (averages from 1950-2000; www.worldclim.org). We removed those with absolute Pearson correlation coefficients $>0.8$ in order to eliminate multi-collinearity effects in the parameter estimates of species distribution models (Sheppard, 2013; Porfirio, 2014). The resulting eight bioclimatic variables (the same as future bioclimatic 
variables) can influence the distribution and physiological performance of invasive weeds (Sheppard, 2013; Table A2). We used the average values of four global climate models for the 2080s (2071-2099; GCMs; i.e., bcc_csm1_1, csiro_mk3_6_0, gfdl_cm3 and mohc_hadgem2_es) and two greenhouse gas concentration scenarios, i.e., Representative Concentration Pathways (RCPs): 4.5 (mean: 780 ppm; range: 595 to 1005 by 2100) and 8.5 (mean: 1685 ppm; range: 1415 to 1910 by 2100; IPCC 5th Assessment Report) to model the future potential distributions of invasive weeds in the 2080s (2071-2099; www.ccafs-climate.org; Liang and Fei, 2014). RCP 4.5 is different from RCP 8.5 in that RCP 8.5 has a greater cumulative concentration of carbon dioxide than RCP 4.5. Thus, RCP 8.5 predicts a different climate due to anthropogenic accumulation of greenhouse gases and other pollutants. RCP 8.5 and RCP 4.5 were used as the high and low concentration scenarios, respectively (http://www.ipcc.ch/). We used bioclimatic variables at four levels of resolution (0.5, 2.5, 5.0 and 10.0 arc-minutes, namely, $1-256 \mathrm{~km}^{2}$ ) because these are the most commonly used data types in SDMs.

\section{Species distribution modelling}

The

Maxent

software

(ver.

3.3.3k;

http://biodiversityinformatics.amnh.org/open_source/maxent/) was used to model the current and future potential distributions of the 10 invasive weeds across four spatial scales $(0.5,2.5,5.0$ and 10.0 arc-minute resolutions; Franklin et al., 2013). Maxent estimated the function of the potential distributions of the 10 invasive weeds based on maximum entropy and then modeled the geographic locations of the distributions based on environmental variables (Phillips and Dudík, 2008; Elith et al., 2011). Pixels in the Maxent results map with a value of 1 have the highest possibility of the species being located there, while pixels with a value of 0 have the lowest possibility of the species being located there (Phillips and Dudík, 2008; Elith et al., 2011). The pixel value reflects the potential distribution that was used to evaluate the risk of invasive weeds for nature reserves (Hoffman et al., 2010; Bean et al., 2014).

Climatic variables at four arc-minute resolutions were used as environmental input layers in Maxent. We used a 4-fold cross-validation approach to divide the presence dataset into 4 approximately equal partitions, and used $75 \%$ of the occurrence points for each species to train the model and the remaining $25 \%$ were used to test the model (each run used a different random sample of points; Merow et al., 2013). We set the regularization multiplier (beta) to 2.0 to produce a smooth and general response (Radosavljevic and Anderson, 2014). Auto features were used and other values were kept at default settings of Elith et al. (2011). The importance of bioclimatic variables was tested using the jackknife method (Phillips and Dudík, 2008; Elith et al., 2011).

The receiver operating characteristic (ROC) curves evaluated each value of the prediction result as a possible judging threshold. We assessed the performance of the Maxent model using the area under the ROC curve (AUC; Phillips and Dudík, 2008). This statistic regards each value of the estimate as a possible threshold based on the corresponding sensitivity and specificity when randomly selected background points are removed from the dataset. To ensure the high precision of SDM on four spatial scales, we only used SDMs with AUC values greater than 0.7 (Phillips and Dudík, 2008; Elith et al., 2011; Suárez-Seoane et al., 2014). 


\section{Evaluating the spread of invasive weeds in nature reserves}

Alagador et al. (2011) used a fixed threshold to match plant species with a nature reserve when the data were at different resolutions of environmental data. However, some studies have indicated that thresholds are problematic and can produce bias in predictions (Calabrese et al., 2014; Merow et al., 2013). The method of Alagador et al. (2011) and Calabrese et al. (2014) was used to evaluate the possibility of the potential distribution of all 10 invasive weeds in each pixel at the scales of 0.5, 2.5, 5.0 and 10.0 arc-minutes in ArcGIS 10.2, respectively (ESRI, 2014) (Eq. 1):

$$
E_{j}=\sum_{k=1}^{k} p_{i, k}
$$

where $E_{j}$ represents the potential for invasive weeds to be present in each pixel $j ; k$ is the number of species in pixel $j ; i$ is species $i$; and $P_{i, k}$ is the probability of the appropriate potential distribution for species $i$ in pixel $j$.

We also assessed the ability of the 10 invasive weeds to spread in each nature reserve in ArcGIS 10.2 as follows (Araújo et al., 2011; Calabrese et al., 2014; ESRI, 2014) (Eq. 2):

$$
S_{t}=\sum_{j=1} X_{j} Y_{j}
$$

where $S_{t}$ is the ability of all 10 invasive weeds to spread in nature reserve $t ; X_{j}$ represents the potential for the presence of invasive weeds in each pixel $j$ in nature reserve $t ; Y_{j}$ is the distribution area percentage of all invasive weeds in nature reserve $t$.

Several studies have shown that the scale of the data can potentially affect the SDM estimate (Pineda and Lobo, 2012; Franklin et al., 2013; Bean et al., 2014). There is a significant linear relationship between the potential distributions of species and fine and coarse spatial scales of the input data, and the medium prediction results computed by the scales would be stable (Kunin, 1998; Wilson et al., 2004; Franklin et al., 2013). Here, the medium results $\left(S_{t}\right)$ was selected to assess the change in the ability of invasive weeds to spread within a nature reserve under climate change (Franklin et al., 2013).

We calculated the change in the ability of invasive weeds to spread within a nature reserve between the current scenario and the 2080s (in the low and high concentration scenarios) (Eq. 3):

$$
A_{t}=\frac{S_{\text {Future }}-S_{\text {Current }}}{S_{\text {Current }}}
$$

where $A_{t}$ is the change in the ability of invasive weeds to spread in nature reserve $t$ and $S_{\text {Future }}$ and $S_{\text {Current }}$ are the future and current ability of invasive weeds to spread in nature reserve $t$.

Finally, we assessed the aggressiveness of each invasive weed by calculating the average values of the potential distribution possibilities of pixels within 333 studied nature reserves in China at medium scales. 


\section{Results}

The WDPA identified 333 Chinese nature reserves with an area greater than $256 \mathrm{~km}^{2}$ that we sampled for our study (Fig. 1). There was no significant correlation between the number of invasive weed locations and AUC $(P>0.05)$. However, AUC measurements of SDM accuracy were greater than 0.9 (from 0.9030 to 0.9816 ; Table Al), indicating highly accurate predictions (Fig. 2). The most important variables for the 10 invasive weeds across all of the spatial scales were temperature seasonality and mean diurnal range (Table A3). We found no significant differences in the importance of bioclimatic variables for any of the species associated with changes in the spatial scales (correlation coefficient $(\mathrm{R})>0.935$ across all the scales; $P<0.001$; Table A3). However, the response of all the species to particular bioclimatic variables differed between scales (Table A3). For example, the average temperature seasonality range changed quite a bit from 0.5 to 10.0 arc-minutes for all the invasive weeds (from $26.660 \pm 12.994$ to 30.527 \pm 13.388; Table A3).

The average ability of invasive weeds to spread in nature reserves would logically increase by using a coarser spatial scale (e.g., from 0.5 to 10.0 arc-minutes) (Fig. 3). Invasive weeds were able to increase their distribution the most using a data scale of 10.0 arc-minutes, and they increased their distribution the least using a scale of 0.5 arcminutes (Fig. 3). We found that Maxent predictions of the spread of invasive weeds were unstable. In other words, they fluctuated when using different data scales (Figs. 3 and $A 1$ in the Appendix). Jiaxi is a good example to show the various results of different data scales (Fig. Al). We found that using 2.5 arc-minute data could have the medium results to estimate invasive weed distributions in nature reserves at all data scales in the present and future (Fig. 3). Therefore, we selected the 2.5 arc-minute data as the appropriate data scale to evaluate the risk of invasive weed spread in Chinese nature reserves under climate change.

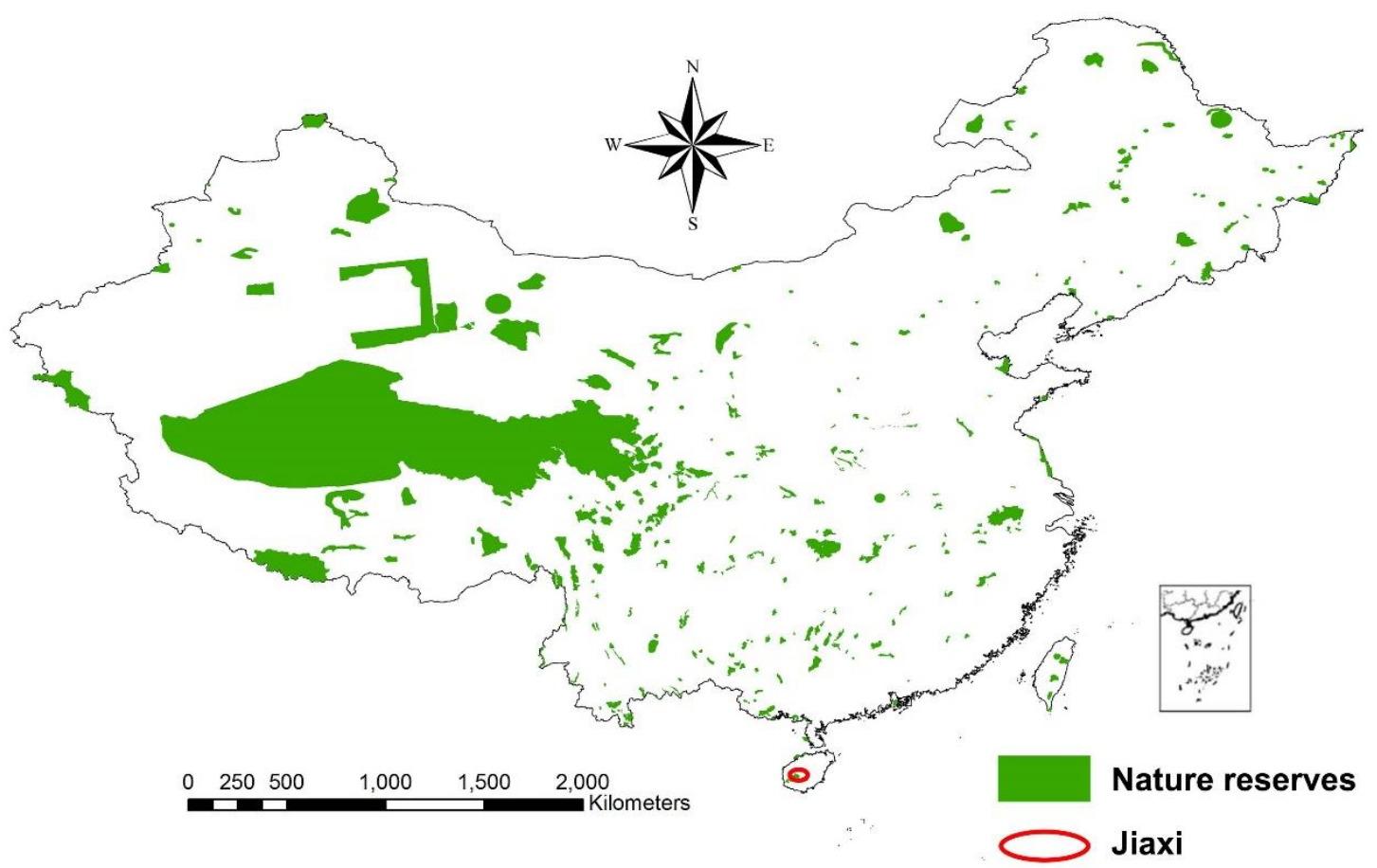

Figure 1. Locations of the sampled nature reserves in China 


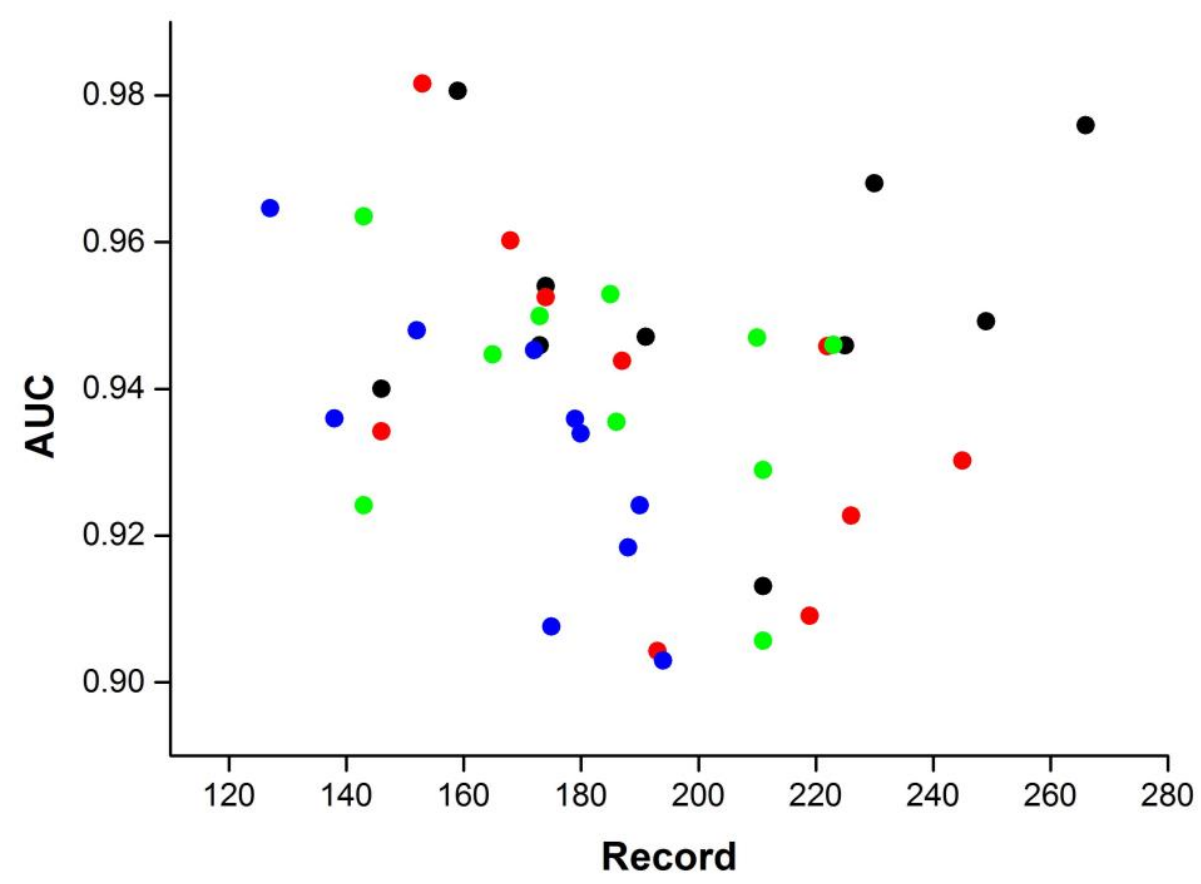

Figure 2. The number of occurrence records and AUC values for 10 invasive weeds when using these different data scales. The black points represent 0.5 arc-minutes; the red points represent 2.5 arc-minutes; the green points represent 5.0 arc-minutes; the blue points represent 10.0 arcminutes

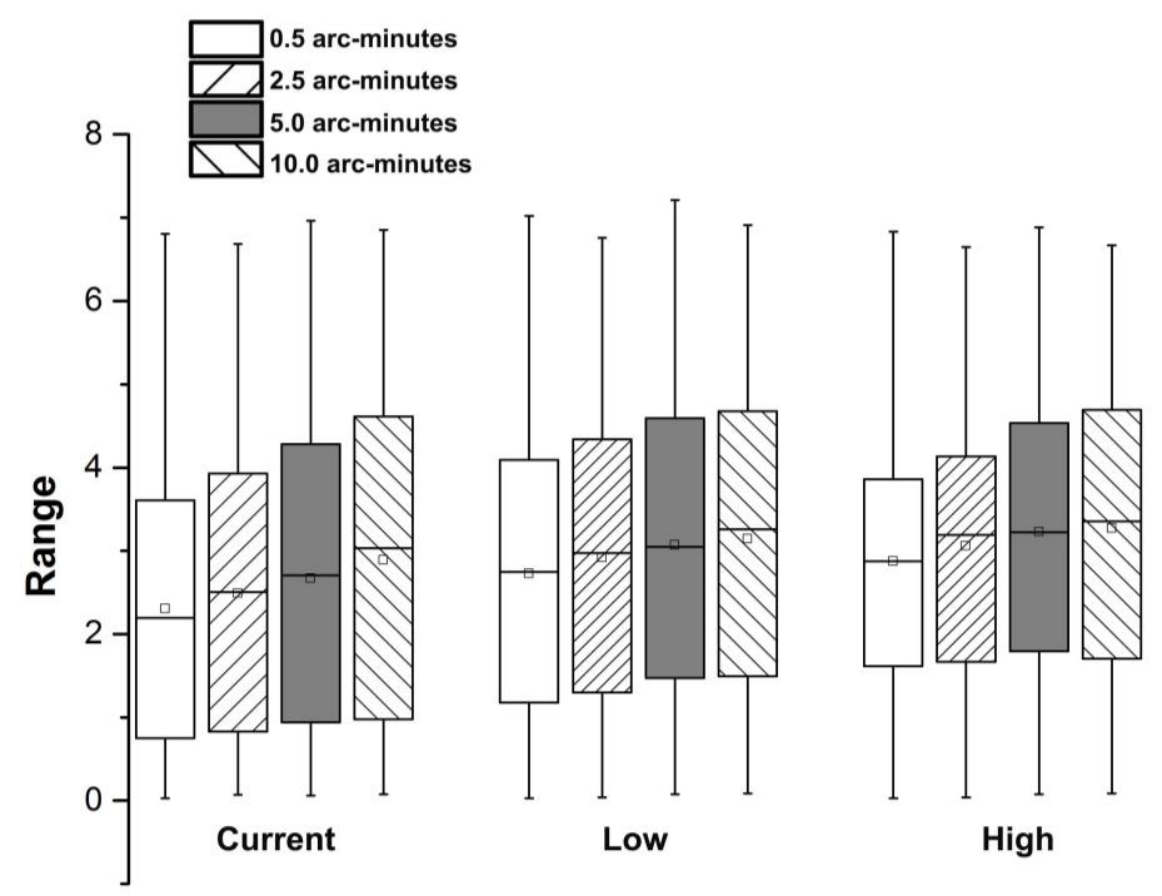

Figure 3. The ability of invasive weeds to spread in nature reserves modeled using different spatial scales in current, low and high gas-concentration scenarios. Range: the ability of invasive weeds to spread in nature reserves bounded by horizontal bars; Current: present day; Low: low-gas-concentration scenario predicted into the future; High: high-gas-concentration scenario predicted into the future. The block point of the box is the mid-value value of the range and the line of box is the mean value of the range 
There was a significantly positive relationship between the spread of invasive weeds in nature reserves with low and high concentration scenarios, suggesting pressure from invasive plants will continue at a similar rate even when different data scales are considered at either low and high concentration scenarios $\left(\mathrm{R}^{2}>0.943 ; P<0.001 ; \mathrm{R}^{2}\right.$ of 2.5 arc-minutes: $0.9618 ; P<0.001)$. Furthermore, the average increase in the ability of invasive weeds to spread within nature reserves was larger in the high concentration scenario than the low concentration scenario ( $+70.25 \%$ (high) $v s .+37.08 \%$ (low); Table A4). Hence, we used a high concentration scenario to map the spread risk of invasive weeds in nature reserves.

We found that $M$. sativa had the largest ability to spread within nature reserves, and A. spinosusin had the smallest spread ability in current and high concentration scenarios (Table 1). Meanwhile, D. carota and M. sativa would have the most significant increasing trends of spread risk under climate change (Table 1). Nature reserves with a high risk of invasive weed spread (e.g., Wuzhishan, Jiaxi, Jianfengling (Hainan province) and Tawushan (Sichuan province)) were mainly distributed in southern China (Fig. 4a; Table A4). These nature reserves are currently dominated by invasive weeds and our estimates predict many of them will continue to be so in the future (Fig. $4 a$ and $b$; Table A4). We found that 291 of 333 nature reserves would be at higher risk for all 10 invasive weeds in the high concentration scenarios than in the present day (Fig. 4; Table A4). In addition, 303 of 333 nature reserves would be at higher risk of all 10 invasive weeds in the low concentration scenarios (Table A4). We found that nature reserves that had the highest increases in their risk for invasive weeds in the high concentration scenario were distributed in southwestern, northwestern and northeastern China (Fig. 4c; Table A4). In southern China, nature reserves had increased risk of invasive weeds, but the change in risk was not as large as in the rest of the country (Fig. 4). Jiaxi and Wuzhishan had the highest risk of all 10 invasive weeds in the current and future concentration scenarios (Table A4), and Kekexili and Aerjinshan had the highest increases in their risk for invasive weeds under climate change (Table A4).

Table 1. Potential risk of the spread of 10 invasive weeds in Chinese nature reserves in the present day and high gas-concentration scenario at a spatial scale of 2.5 arc-minutes. Current indicates the spread of 10 invasive weeds in the nature reserves in the present days. High indicates the spread of 10 invasive weeds in the nature reserves in the high concentration scenario. High-change indicates the changes in the ability of invasive weeds to spread in the nature reserves in the high concentration scenario

\begin{tabular}{c|c|c|c|c}
\hline Species & Family & Current & High & High-change \\
\hline Bidens pilosa & Compositae & 0.042 & 0.064 & 0.535 \\
Amaranthus spinosus & Amaranthaceae & 0.024 & 0.044 & 0.807 \\
Cassia mimosoides & Leguminosae & 0.035 & 0.048 & 0.372 \\
Conyza canadensis & Compositae & 0.089 & 0.176 & 0.988 \\
Daucus carota & Umbelliferae & 0.078 & 0.174 & 1.244 \\
Euphorbia hirta & Euphorbiaceae & 0.027 & 0.047 & 0.721 \\
Medicago sativa & Leguminosae & 0.184 & 0.428 & 1.325 \\
Physalis angulata & Solanaceae & 0.042 & 0.066 & 0.584 \\
Sonchus oleraceus & Compositae & 0.099 & 0.188 & 0.905 \\
Vicia sativa & Leguminosae & 0.117 & 0.235 & 1.009 \\
\hline
\end{tabular}



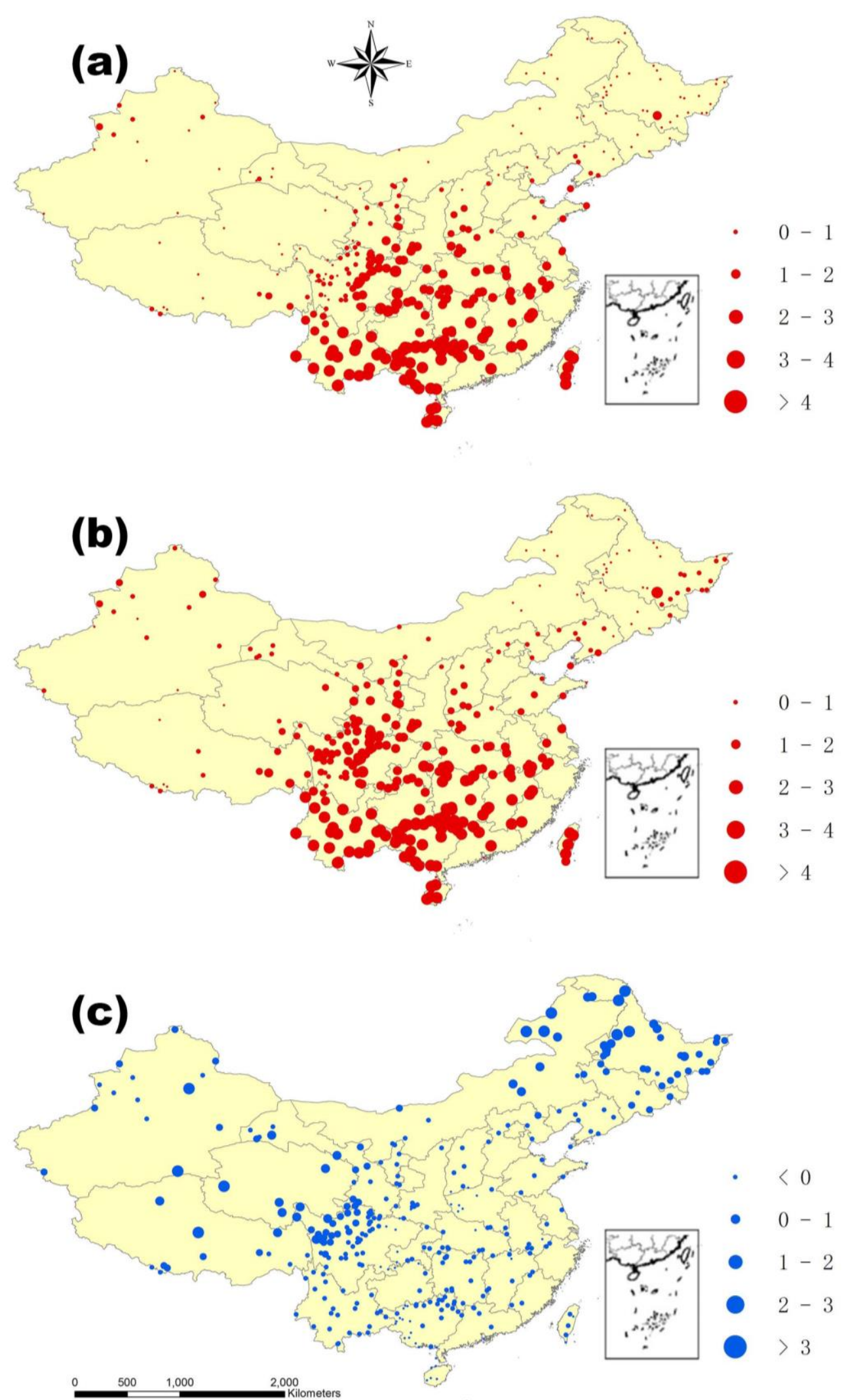

Figure 4. The spread of invasive weeds in nature reserves (a) in the present day and (b) in high gas-concentration scenario at a spatial scale of 2.5 arc-minutes and (c) the changes in the spread of invasive weeds in the high gas-concentration scenario at a spatial scale of 2.5 arcminutes 


\section{Discussion}

Our study is an example of how SDMs can be applied to estimate the risk of weed spread in nature reserves with the different scales. Our results showed that using different spatial scales results in different estimates of invasive weeds distributions in current, low and high concentration future scenarios. This indicates that the spatial scale may under- or over- estimate the ability of invasive weeds to increase their distribution in nature reserves. We also found that the risk of invasive weeds in nature reserves was largest at scales of 10.0 arc-minutes. Thus, SDM prediction uncertainty caused by spatial scales could result in inaccurate estimates of invasive weed distributions and their effect on nature reserves. Previous studies have determined the appropriate scale of data to use in SDMs by comparing relationships of potential distributions between fine and coarse scales and subjectively choosing the "best" data scale based on the results (Franklin et al., 2013; Suárez-Seoane et al., 2014). Franklin et al. (2013) selected the appropriate scale by computing the extent and location of the predicted distribution area under current climate conditions depending on the differences in the estimates between fine and coarse scales. The selection of an appropriate data scale should incorporate the variance found when using different scales in SDMs (based on Fig. 2) and stabilize the predicted distribution of invasive weeds (Franklin et al., 2013). Hence, by comparing the SDM results of different scales, we used 2.5 arc-minutes, the second-finest scale (also, the medium scale), to evaluate invasive weed risk in nature reserves under climate change scenarios.

Millions of dollars have been invested in the global control of invasive weeds and many scientists have proposed methods to prevent and control the invasion of invasive weeds (Dewey et al., 1995; Rinella and Luschei, 2007). Some scientists have proposed designing long-term management plans at the regional or national scale to mitigate weed spread due to climate change (Chejara et al., 2010; Bohan et al., 2011; Sheppard, 2013; Qin et al., 2014). However, few studies paid attention to the spread of invasive weeds in nature reserves at the national scale. The spread of invasive weeds into nature reserves may cause serious problems (Van Wilgen et al., 2012; Lindenmayer et al., 2015). The invasive weeds can displace native species, alter community structure and ecosystem functions, and cause landscape change and habitat fragmentation (Lindenmayer et al., 2015; Thalmann et al., 2015). Consequently, nature reserves may lose their function of protecting concerned species, habitats or ecosystems (Ingwell and Bosque-Pérez, 2015; Thalmann et al., 2015). We found that nature reserves in southern China are currently dominated by invasive weeds and our estimates predict most of them will continue to be so in the future. Our data supports the need for long-term monitoring of these nature reserves to prevent the spread of invasive weeds due to climate change (Wang et al., 2017). Our finding that the ability of invasive weeds to spread within nature reserves would increase more severely in the high concentration scenario than the low concentration scenario indicated that climate change due to the increasing gas concentration may facilitate the spread of invasive weeds in nature reserves. More importantly, we found a significant relationship between increased invasive weed distributions and low and high concentration scenarios, suggesting we should prioritize the prevention and control of invasive weeds now to lessen their impact on nature reserves in the future (Rannow et al., 2014). Therefore, the prevention and control of invasive weeds in nature reserves is extremely urgent now. The challenge for biological conservationists will be in minimizing the opportunities for invasive plant species to be introduced into nature reserves under climate change. Based on the assessment of expansion risk for invasive weeds and nature reserves, we propose the following measures: (1) detailed monitoring of climate change, (2) improvement of 
effective management for human activities near or inside nature reserves, and (3) control of the introduction of invasive weeds with a high ability to naturally disperse (Foxcroft et al., 2017; Merow et al., 2017).

Our suggestion is that researchers integrate model evaluation of several different spatial scales $(0.5,2.5,5.0$ and 10.0 scales widely used in SDM studies) into their SDM analyses on invasive weeds. Although our study did not validate the Maxent estimates with ground truthing or ecological monitoring this work should be prioritized as a way to test our approach for quantifying invasive species risk (Alagador et al., 2011). Using the correct scale for SDM may lead to more accurate predictions that allow researchers and land managers to make reasonable decisions regarding the management of invasive weeds (Costa et al., 2013; Sheppard, 2013; Qin et al., 2014). Therefore, studies on the effect of data scales on SDMs must continue. We hope that future studies can expand the application of SDMs to provide practical suggestions for mitigating the impact of scale effects on SDM predictions of weeds.

\section{Conclusion}

We put forward a simple method to balance various results modeled by different spatial scales for avoiding the over- or under-estimation of SDM results due to the selection of spatial scales, and take the impact of different scales on SDM results into consideration for invasion risk of weeds. Nature reserves with a high risk of invasive weed spread were mainly distributed in southern China. We should prioritize the prevention and control of invasive weeds now to lessen their impact on nature reserves in the future. Here, we proposed the useful suggestions for the evaluation of risk of invasive species: (1) we need to compute two indicators: the ability of invasive weeds to spread in nature reserves and spread potential of invasive weeds for nature reserves; (2) we should balance the various impacts of different spatial scales on the results of SDMs; (3) we should determine the regional scales of spread risk of invasive weeds under climate change. Finally, we hope that future studies can expand the application of SDMs to provide feasible suggestions for risk evaluation of invasive species under climate change.

Acknowledgements. This work has been supported by the National Natural Science Foundation of China (No. 31800449 and 31800464) and the Basic Research Project of Qinghai Province, China (No. 2019-ZJ936Q and 2019-ZJ-960Q).

Disclosure statement. No potential conflict of interests was reported by the authors

\section{REFERENCES}

[1] Alagador, D., Martins, M. J., Cerdeira, J. O., Cabeza, M., Araújo, M. B. (2011): A probability-based approach to match species with reserves when data are at different resolutions. - Biological Conservation 144: 811-820.

[2] Araújo, M. B., Alagador, D., Cabeza, M., Nogués-Bravo, D., Thuiller, W. (2011): Climate change threatens European conservation areas. - Ecology Letters 14: 484-492.

[3] Bean, W. T., Prugh, L. R., Stafford, R., Butterfield, H. S., Westphal, M., Brashares, J. S. (2014): Species distribution models of an endangered rodent offer conflicting measures of habitat quality at multiple scales. - Journal of Applied Ecology 51: 1116-1125. 
[4] Beck, J., Ballesteros-Mejia, L., Nagel, P., Kitching, I. J. (2013): Online solutions and the 'Wallacean shortfall': what does GBIF contribute to our knowledge of species' ranges? - Diversity and Distributions 19: 1043-1050.

[5] Beck, J., Böller, M., Erhardt, A., Schwanghart, W. (2014): Spatial bias in the GBIF database and its effect on modeling species' geographic distributions. - Ecological Informatics 19: 10-15.

[6] Bird, T. J., Bates, A. E., Lefcheck, J. S., Hill, N. A., Thomson, R. J., Edgar, G. J., Pecl, G. T. (2014): Statistical solutions for error and bias in global citizen science datasets. Biological Conservation 173: 144-154.

[7] Bohan, D. A., Boursault, A., Brooks, D. R., Petit, S. (2011): National-scale regulation of the weed seedbank by carabid predators. - Journal of Applied Ecology 48: 888-898.

[8] Calabrese, J. M., Certain, G., Kraan, C., Dormann, C. F. (2014): Stacking species distribution models and adjusting bias by linking them to macroecological models. Global Ecology and Biogeography 23: 99-112.

[9] Chejara, V. K., Kriticos, D. J., Kristiansen, P., Sindel, B. M., Whalley, R. D. B., Nadolny, C. (2010): The current and future potential geographical distribution of Hyparrhenia hirta. - Weed Research 50: 174-184.

[10] Costa, H., Medeiros, V., Azevedo, E. B., Silva, L. (2013): Evaluating ecological-niche factor analysis as a modelling tool for environmental weed management in island systems. - Weed Research 53: 221-230.

[11] Crall, A. W., Jarnevich, C. S., Young, N. E., Panke, B. J., Renz, M., Stohlgren, T. J. (2015): Citizen science contributes to our knowledge of invasive plant species distributions. - Biological Invasions 17: 2415-2427.

[12] Dewey, S. A., Jenkins, M. J., Tonioli, R. C. (1995): Wildfire suppression: a paradigm for noxious weed management. - Weed Technology 9: 621-627.

[13] Elith, J., Phillips, S. J., Hastie, T., Dudík, M., Chee, Y. E., Yates, C. J. (2011): A statistical explanation of MaxEnt for ecologists. - Diversity and Distributions 17: 43-57.

[14] ESRI (2014): ArcGIS Desktop. - http://resources.arcgis.com/en/help/main/10.2.

[15] Foxcroft, L. C., Pyšek, P., Richardson, D. M., Genovesi, P., MacFadyen, S. (2017): Plant invasion science in protected areas: progress and priorities. - Biological Invasions 19: 13531378.

[16] Franklin, J., Davis, F. W., Ikegami, M., Syphard, A. D., Flint, L. E., Flint, A. L., Hannah, L. (2013): Modeling plant species distributions under future climates: how fine scale do climate projections need to be? - Global Change Biology 19: 473-483.

[17] Hoffman, J. D., Aguilar-Amuchastegui, N., Tyre, A. J. (2010): Use of simulated data from a process-based habitat model to evaluate methods for predicting species occurrence. - Ecography 33: 656-666.

[18] Ingwell, L. L., Bosque-Pérez, N. A. (2015): The invasive weed Ventenata dubia is a host of Barley yellow dwarf virus with implications for an endangered grassland habitat. Weed Research 55: 62-70.

[19] Jiménez-Alfaro, B., Draper, D., Nogués-Bravo, D. (2012): Modeling the potential area of occupancy at fine resolution may reduce uncertainty in species range estimates. Biological Conservation 147: 190-196.

[20] Kunin, W. E. (1998): Extrapolating species abundance across spatial scales. - Science 281: 1513-1515.

[21] Li, Y. H. (1998): Chinese Weeds. - China Agriculture Press, Beijing.

[22] Liang, L., Fei, S. (2014): Divergence of the potential invasion range of emerald ash borer and its host distribution in North America under climate change. - Climatic Change 122: 735-746.

[23] Lindenmayer, D. B., Wood, J., MacGregor, C., Buckley, Y. M., Dexter, N., Fortescue, M., Catford, J. A. (2015): A long-term experimental case study of the ecological effectiveness and cost effectiveness of invasive plant management in achieving 
conservation goals: Bitou Bush control in Booderee National Park in Eastern Australia. PloS One 10:e 0128482.

[24] Merow, C., Smith, M. J., Silander, J. A. (2013): A practical guide to MaxEnt for modeling species' distributions: what it does, and why inputs and settings matter. Ecography 36: 1058-1069.

[25] Merow, C., Bois, S. T., Allen, J. M., Xie, Y., Silander, J. A. (2017): Climate change both facilitates and inhibits invasive plant ranges in New England. - Proceedings of the National Academy of Sciences 201609633.

[26] Metzger, M. J., Bunce, R. G. H., Jongman, R. H. G., Mücher, C. A., Watkins, J. W. (2005): A climatic stratification of the environment of Europe. - Global Ecology and Biogeography 14: 549-563.

[27] Phillips, S. J., Dudík, M. (2008): Modeling of species distributions with Maxent: new extensions and a comprehensive evaluation. - Ecography 31: 161-175.

[28] Pineda, E., Lobo, J. M. (2012): The performance of range maps and species distribution models representing the geographic variation of species richness at different resolutions. - Global Ecology and Biogeography 21: 935-944.

[29] Porfirio, L. L., Harris, R. M., Lefroy, E. C., Hugh, S., Gould, S. F., Lee, G., Mackey, B. (2014): Improving the use of species distribution models in conservation planning and management under climate change. - PloS One 9: e113749.

[30] Qin, Z., DiTommaso, A., Wu, R. S., Huang, H. Y. (2014): Potential distribution of two Ambrosia species in China under projected climate change. - Weed Research 54: 520-531.

[31] Radosavljevic, A., Anderson, R. P. (2014): Making better Maxent models of species distributions: complexity, overfitting and evaluation. - Journal of Biogeography 41: 629-643.

[32] Rahbek, C., Graves, G. R. (2001): Multiscale assessment of patterns of avian species richness. - Proceedings of the National Academy of Sciences 98: 4534-4539.

[33] Rannow, S., Macgregor, N. A., Albrecht, J., Crick, H. Q., Förster, M., Heiland, S., Sienkiewicz, J. (2014): Managing protected areas under climate change: challenges and priorities. - Environmental Management 54: 732-743.

[34] Rinella, M. J., Luschei, E. C. (2007): Hierarchical Bayesian methods estimate invasive weed impacts at pertinent spatial scales. - Biological Invasions 9: 545-558.

[35] Sheppard, C. S. (2013): How does selection of climate variables affect predictions of species distributions? A case study of three new weeds in New Zealand. - Weed Research 53: 259-268.

[36] Stratonovitch, P., Storkey, J., Semenov, M. A. (2012): A process-based approach to modelling impacts of climate change on the damage niche of an agricultural weed. Global Change Biology 18: 2071-2080.

[37] Suárez-Seoane, S., Virgós, E., Terroba, O., Pardavila, X., Barea-Azcón, J. M. (2014): Scaling of species distribution models across spatial resolutions and extents along a biogeographic gradient. The case of the Iberian mole Talpa occidentalis. - Ecography 37: 279-292.

[38] Thalmann, D. J. K., Kikodze, D., Khutsishvili, M., Kharazishvili, D., Guisan, A., Broennimann, O., Müller-Schärer, H. (2015): Areas of high conservation value in Georgia: present and future threats by invasive alien plants. - Biological Invasions 17: 1041-1054.

[39] Van Wilgen, B. W., Forsyth, G. G., Le Maitre, D. C., Wannenburgh, A., Kotzé, J. D., van den Berg, E., Henderson, L. (2012): An assessment of the effectiveness of a large, national-scale invasive alien plant control strategy in South Africa. - Biological Conservation 148: 28-38.

[40] Vanderhoeven, S., Piqueray, J., Halford, M., Nulens, G., Vincke, J., Mahy, G. (2011): Perception and understanding of invasive alien species issues by nature conservation and horticulture professionals in Belgium. - Environmental Management 47: 425-442. 
[41] Velásquez-Tibatá, J., Salaman, P., Graham, C. H. (2013): Effects of climate change on species distribution, community structure, and conservation of birds in protected areas in Colombia. - Regional Environmental Change 13: 235-248.

[42] Wan, J. Z., Wang, C. J. (2018): Expansion risk of invasive plants in regions of high plant diversity: A global assessment using 36 species. - Ecological Informatics 46: 8-18.

[43] Wan, J. Z., Wang, C. J., Yu, F. H. (2016): Impacts of the spatial scale of climate data on the modeled distribution probabilities of invasive tree species throughout the world. Ecological Informatics 36: 42-49.

[44] Wang, C. J., Wan, J. Z., Qu, H., Zhang, Z. X. (2017): Modelling plant invasion pathways in protected areas under climate change: implication for invasion management. - Web Ecology 17: 69-77.

[45] Wang, Z., Rahbek, C., Fang, J. (2012): Effects of geographical extent on the determinants of woody plant diversity. - Ecography 35: 1160-1167.

[46] Wilson, R. J., Thomas, C. D., Fox, R., Roy, D. B., Kunin, W. E. (2004): Spatial patterns in species distributions reveal biodiversity change. - Nature 432: 393-396.

[47] Xu, H. G., Qiang, S. (2011): China's Invasive Alien Species. - Science Press, Beijing.

[48] Zhang, H. X., Zhang, M. L. (2014): Insight into distribution patterns and conservation planning in relation to woody species diversity in Xinjiang, arid northwestern China. Biological Conservation 177: 165-173.

\section{APPENDIX}

Table A1. Occurrence records and AUC values of study species. Records: the number of recorded occurrences of each study species; AUC: AUC values of study species. 0.5: 0.5 arc-minute, 2.5: 2.5 arc-minutes, 5.0: 5.0 arc-minutes, 10.0: 10.0 arc-minutes

\begin{tabular}{|c|c|c|c|c|c|c|c|c|c|}
\hline \multirow{2}{*}{ Species } & \multirow{2}{*}{ Family } & \multicolumn{2}{|c|}{0.5 arc-minutes } & \multicolumn{2}{|c|}{2.5 arc-minutes } & \multicolumn{2}{|c|}{5.0 arc-minutes } & \multicolumn{2}{|c|}{10.0 arc-minutes } \\
\hline & & Records & AUC & Records & AUC & Records & AUC & Records & AUC \\
\hline Bidens pilosa & Compositae & 266 & 0.9759 & 245 & 0.9302 & 223 & 0.946 & 190 & 0.9241 \\
\hline Amaranthus spinosus & Amaranthaceae & 159 & 0.9806 & 153 & 0.9816 & 143 & 0.9635 & 127 & 0.9646 \\
\hline Cassia mimosoides & Leguminosae & 173 & 0.9459 & 168 & 0.9602 & 165 & 0.9447 & 152 & 0.948 \\
\hline Conyza canadensis & Compositae & 211 & 0.9131 & 193 & 0.9043 & 186 & 0.9355 & 175 & 0.9076 \\
\hline Daucus carota & Umbelliferae & 174 & 0.954 & 174 & 0.9525 & 173 & 0.9499 & 172 & 0.9453 \\
\hline Euphorbia hirta & Euphorbiaceae & 249 & 0.9492 & 226 & 0.9227 & 211 & 0.9289 & 179 & 0.9359 \\
\hline Medicago sativa & Leguminosae & 191 & 0.9471 & 187 & 0.9438 & 185 & 0.9529 & 180 & 0.9339 \\
\hline Physalis angulata & Solanaceae & 230 & 0.968 & 219 & 0.9091 & 210 & 0.947 & 188 & 0.9184 \\
\hline Sonchus oleraceus & Compositae & 225 & 0.9459 & 222 & 0.9458 & 211 & 0.9057 & 194 & 0.903 \\
\hline Vicia sativa & Leguminosae & 146 & 0.94 & 146 & 0.9342 & 143 & 0.9241 & 138 & 0.936 \\
\hline
\end{tabular}

Table A2. WorldClim bioclimatic variables used in the analysis. Bioclimatic variables were used as environmental layers for the species potential habitat distribution models in Maxent; $C$ of $V$ represents the coefficient of variation

\begin{tabular}{l|c|c}
\hline Code & Bioclimatic variables & Unit \\
\hline Bio1 & Annual mean temperature & ${ }^{\circ} \mathrm{C}$ \\
Bio2 & Mean diurnal range & ${ }^{\circ} \mathrm{C}$ \\
Bio4 & Temperature seasonality & $\mathrm{SD}^{*} 100$ \\
Bio8 & Mean temperature of the wettest quarter & ${ }^{\circ} \mathrm{C}$ \\
Bio10 & Mean temperature of the warmest quarter & ${ }^{\circ} \mathrm{C}$ \\
Bio12 & Annual precipitation & $\mathrm{mm}$ \\
Bio14 & Precipitation of the driest month & $\mathrm{mm}$ \\
Bio15 & Precipitation seasonality & $\mathrm{C}$ of V \\
\hline
\end{tabular}


Table A3. The average and standard deviation values of the importance of bioclimatic variables based on Maxent jackknife test. The codes that were used in this table are defined in Table A2

\begin{tabular}{c|c|c|c|c}
\hline Code & 0.5 arc-minutes & $\mathbf{2 . 5}$ arc-minutes & $\mathbf{5 . 0}$ arc-minutes & 10.0 arc-minutes \\
\hline Bio1 & $19.986 \pm 13.494$ & $18.055 \pm 14.905$ & $17.966 \pm 10.469$ & $12.517 \pm 11.458$ \\
Bio2 & $20.470 \pm 12.681$ & $20.359 \pm 15.160$ & $24.238 \pm 17.660$ & $23.131 \pm 14.188$ \\
Bio4 & $29.833 \pm 14.493$ & $30.527 \pm 13.388$ & $26.660 \pm 12.994$ & $30.508 \pm 10.700$ \\
Bio8 & $4.129 \pm 3.577$ & $4.529 \pm 3.807$ & $3.573 \pm 3.530$ & $5.662 \pm 4.441$ \\
Bio10 & $4.987 \pm 3.373$ & $4.283 \pm 1.651$ & $5.419 \pm 3.246$ & $5.854 \pm 4.117$ \\
Bio12 & $7.912 \pm 5.462$ & $10.075 \pm 6.505$ & $8.288 \pm 3.559$ & $11.475 \pm 5.658$ \\
Bio14 & $3.343 \pm 2.016$ & $2.954 \pm 2.913$ & $3.928 \pm 2.781$ & $3.866 \pm 3.030$ \\
Bio15 & $9.339 \pm 10.249$ & $9.217 \pm 7.524$ & $9.930 \pm 9.652$ & $6.986 \pm 9.917$ \\
\hline
\end{tabular}

(a) 0.5

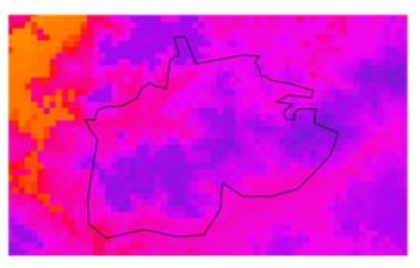

(c) 5.0

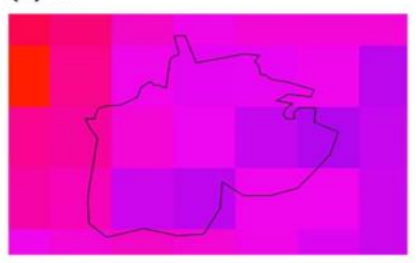

(b) 2.5

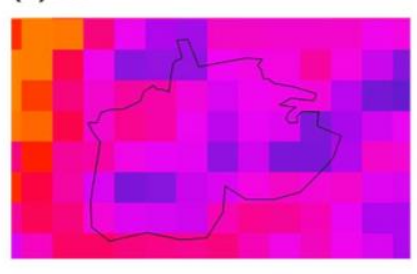

(d) 10.0
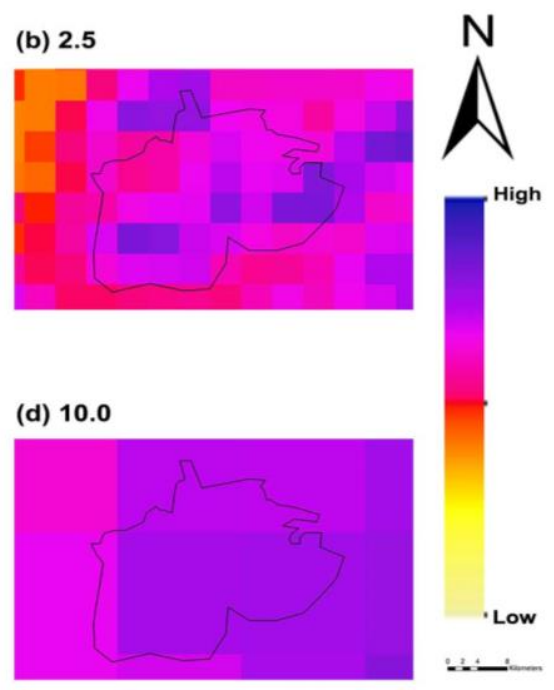

Figure A1. The spread of invasive weeds in Jiaxi nature reserve in the present day at different spatial scales (i.e., 0.5, 2.5, 5.0 and 10.0 arc-minute resolutions)

Table A4. Potential risk of the spread of 10 invasive weeds in Chinese nature reserves at a spatial scale of 2.5 arc-minutes. Name refers to the names of nature reserves based on WDPA database. Current refers to the spread of 10 invasive weeds in the nature reserves in current concentration scenario. Low signifies the spread of 10 invasive weeds in the nature reserves in the low concentration scenario. High indicates the spread of 10 invasive weeds in the nature reserves in the high concentration scenario. Low-change: the changes in the ability of invasive weeds to spread in the nature reserves in the low concentration scenario; High-change: the changes in the ability of invasive weeds to spread in the nature reserves in the high concentration scenario

\begin{tabular}{c|c|c|c|c|c}
\hline Name & Current & Low & High & Low-change & High-change \\
\hline Aerjinshan & 0.068180366 & 0.1775214 & 0.3933055 & 1.603702655 & 4.76860353 \\
Ailaoshan & 4.218334732 & 4.9194589 & 5.5215848 & 0.166208756 & 0.308948946 \\
An'jilongwangshan & 3.610529992 & 4.000187 & 3.7872113 & 0.107922385 & 0.048935006 \\
Anxijihanhuangmo & 0.811199047 & 1.1095888 & 1.6160121 & 0.367837899 & 0.99212771 \\
Anzihe & 3.473078712 & 3.9443094 & 4.0854224 & 0.13568097 & 0.176311492 \\
A'rengou & 1.389479549 & 2.8543233 & 3.5136993 & 1.054239159 & 1.528788065 \\
Badagongshan & 3.578065628 & 4.0938891 & 3.972425 & 0.144162664 & 0.110215802 \\
Baidongheshuiyuanlin & 4.884217508 & 4.6070336 & 4.3879747 & -0.056750935 & -0.101601292 \\
Baihe (Sichuan) & 2.355475977 & 3.2660591 & 3.2499793 & 0.386581367 & 0.379754806 \\
\hline
\end{tabular}




\begin{tabular}{|c|c|c|c|c|c|}
\hline Name & Current & Low & High & Low-change & High-change \\
\hline Baijitan & 1.805230733 & 2.4081005 & 2.4963897 & 0.333957181 & 0.382864614 \\
\hline Baimaxueshan & 2.38405453 & 3.1118643 & 3.1947595 & 0.30528235 & 0.340053031 \\
\hline Baishuijiang & 3.507968046 & 4.0925835 & 3.7023217 & 0.166653586 & 0.055403485 \\
\hline Baiyang & 2.526666136 & 3.227808 & 3.2619489 & 0.277496838 & 0.291009071 \\
\hline Bajie & 1.184312121 & 2.0891855 & 2.7071695 & 0.764049749 & 1.285858138 \\
\hline Bamianshan & 4.008368154 & 4.6635722 & 4.6239197 & 0.163459049 & 0.153566619 \\
\hline Banli & 4.943201904 & 4.8011102 & 4.8733824 & -0.028744872 & -0.014124348 \\
\hline Baohuashan & 3.25073457 & 3.4565137 & 3.4192301 & 0.063302348 & 0.051833063 \\
\hline Bayinbuluketiane & 0.166414421 & 0.2370796 & 0.3055153 & 0.424633746 & 0.835870342 \\
\hline Bitahai & 2.231175582 & 2.4913757 & 2.9686196 & 0.116620189 & 0.330518147 \\
\hline Buergenheli & 0.72121909 & 1.3040109 & 1.5471167 & 0.80806487 & 1.145141083 \\
\hline Buliuheshuiyuanlin & 4.69673285 & 4.7488565 & 4.5295667 & 0.011097853 & -0.035592007 \\
\hline Cangshanerhai & 3.959751105 & 4.8609742 & 5.2486132 & 0.227595895 & 0.325490684 \\
\hline Cenwanglaoshanshuiyuanlin & 4.673200934 & 5.0158726 & 4.9457915 & 0.07332697 & 0.05833059 \\
\hline Changbaishan & 0.340824228 & 0.5910087 & 0.8382921 & 0.734057181 & 1.459602432 \\
\hline Changjiangxinluoduanbaijitun (Hubei) & 3.638086006 & 3.9493103 & 3.758875 & 0.085546162 & 0.033201248 \\
\hline Changjigangshidi & 0.281764871 & 0.5188044 & 0.9337151 & 0.841267146 & 2.313809478 \\
\hline Changningzuhai & 4.322759185 & 4.3419296 & 3.900583 & 0.004434764 & -0.097663591 \\
\hline Changqing & 3.019663695 & 3.4678836 & 3.3351798 & 0.148433717 & 0.104487167 \\
\hline Changshagongma & 0.470046796 & 0.9273012 & 1.5938657 & 0.972784854 & 2.390866002 \\
\hline Chaqinsongduo & 0.81403072 & 1.5976287 & 2.5128852 & 0.962614752 & 2.086966055 \\
\hline Chayucibagou & 2.041112011 & 2.9757539 & 3.2698697 & 0.457908181 & 0.602004046 \\
\hline Chayuhu & 0.430203311 & 0.7933017 & 0.9610103 & 0.844015794 & 1.233851473 \\
\hline Chengbiheshuiyuanlin & 4.896073856 & 4.7630283 & 4.5597921 & -0.027173928 & -0.068683963 \\
\hline Chichengdahaituo & 0.829301289 & 0.9031788 & 1.1233997 & 0.089084042 & 0.354633973 \\
\hline Chuandonghe & 4.606035769 & 4.6140348 & 4.3998648 & 0.001736641 & -0.044761044 \\
\hline Cuiyunlanggubai & 3.859620279 & 4.0159084 & 3.5892596 & 0.040493134 & -0.070048518 \\
\hline Dabashan & 3.328029459 & 3.7531105 & 3.5995671 & 0.127727548 & 0.081591117 \\
\hline Dafengmilu (Jiangsu) & 2.90771915 & 3.2236214 & 3.2242437 & 0.108642628 & 0.108856645 \\
\hline Daguisi & 3.264832547 & 3.476791 & 3.4729822 & 0.064921692 & 0.063755078 \\
\hline Daheishan (Heilongjiang) & 0.291439772 & 0.5273876 & 0.8503797 & 0.809593785 & 1.917857416 \\
\hline Dahongjiangshuiyuanlin & 4.71794787 & 4.684868 & 4.6164774 & -0.007011495 & -0.021507332 \\
\hline Dahongshanyinxing & 3.448675483 & 3.4305483 & 3.2224149 & -0.005256274 & -0.065607966 \\
\hline Dahuofangshuiyuanshuiku & 0.956092565 & 1.2316865 & 1.0782893 & 0.288250265 & 0.127808477 \\
\hline Dalaihu & 0.108859393 & 0.2305818 & 0.5355734 & 1.118161728 & 3.91986392 \\
\hline Dalinuoerniaolei & 0.285656861 & 0.5563217 & 0.8753719 & 0.947517375 & 2.064417557 \\
\hline Damingshanshuiyuanlin (Guangxi) & 4.889718323 & 4.9585741 & 5.01487 & 0.014081747 & 0.025594864 \\
\hline Danxianbaidiebei & 4.985318304 & 4.6786053 & 4.8319898 & -0.061523254 & -0.030756011 \\
\hline Daozhendashahe & 3.680527407 & 4.0983071 & 3.9235606 & 0.113510822 & 0.066032165 \\
\hline Dasuganhu & 0.562605599 & 1.0260591 & 1.405613 & 0.823762689 & 1.498398527 \\
\hline Dawanglingshuiyuanlin & 5.014520129 & 4.9281845 & 4.7289345 & -0.017217127 & -0.056951736 \\
\hline Daxiaolangou & 3.590334076 & 3.7437164 & 3.5987411 & 0.042720906 & 0.002341572 \\
\hline Dayaoshanshuiyuanlin (Guangxi) & 4.439299765 & 4.9065495 & 4.6764125 & 0.105253026 & 0.053412193 \\
\hline Dazhongshan & 4.649500182 & 5.4927152 & 5.8394917 & 0.181356057 & 0.255939665 \\
\hline Dianchi & 4.499969969 & 5.1899584 & 5.330356 & 0.153331786 & 0.184531461 \\
\hline Donganshunhuangshan & 3.867737555 & 4.5718572 & 4.8515843 & 0.182049489 & 0.254372674 \\
\hline Dongdongtinghu (Hunan) & 3.886313855 & 4.3183458 & 4.1328029 & 0.111167538 & 0.063424894 \\
\hline Dongzhai niaolei & 3.316473124 & 3.4241928 & 3.4126855 & 0.03248019 & 0.029010449 \\
\hline Dugoula & 0.907013901 & 1.5785688 & 2.674138 & 0.740401992 & 1.948287779 \\
\hline Dunhuang & 0.404149414 & 0.7933638 & 1.2392571 & 0.963045776 & 2.066334027 \\
\hline Em Ei Shan & 3.992729896 & 4.2901553 & 4.1393044 & 0.074491742 & 0.036710348 \\
\hline Fanjingshan (Guizhou) & 3.570361712 & 3.9039159 & 3.9035081 & 0.09342308 & 0.093308862 \\
\hline Fenghuangshan (Heilongjiang) & 0.682192057 & 1.1025248 & 1.5767282 & 0.616150157 & 1.311267309 \\
\hline Fenglin & 0.224479499 & 0.3988635 & 0.6667784 & 0.776837091 & 1.970330934 \\
\hline
\end{tabular}




\begin{tabular}{|c|c|c|c|c|c|}
\hline Name & Current & Low & High & Low-change & High-change \\
\hline Fengtongzhai (Sichuan) & 3.081397331 & 3.6091109 & 3.8951259 & 0.171257878 & 0.264077781 \\
\hline Fengwugou & 0.826358234 & 1.2335944 & 1.7518904 & 0.492808263 & 1.120013244 \\
\hline Foping & 2.894701462 & 3.4591989 & 3.3299122 & 0.195010589 & 0.150347365 \\
\hline Funiushan & 2.804172271 & 2.9782938 & 2.7362375 & 0.062093735 & -0.024226319 \\
\hline Fuyushuiqing (Shuiqing) & 0.256543428 & 0.4779255 & 0.8550919 & 0.862941895 & 2.333127286 \\
\hline Gajinxueshan & 1.066909829 & 2.1621586 & 2.8080534 & 1.026561703 & 1.631950071 \\
\hline Ganjiahu (Xinjiang) & 1.300586638 & 1.5906694 & 1.5038426 & 0.223039937 & 0.156280217 \\
\hline Ganligahai-zecha & 0.997468313 & 2.1067952 & 2.8403099 & 1.112142484 & 1.847518927 \\
\hline Gaoligongshan & 3.134970181 & 3.7814828 & 4.0319559 & 0.206226082 & 0.286122568 \\
\hline Gemu & 0.909843507 & 1.2958836 & 1.6658613 & 0.424292848 & 0.830931679 \\
\hline Genieshenshan & 1.088408407 & 1.7106679 & 2.050123 & 0.571715074 & 0.883597174 \\
\hline Gonggashan (Sichuan) & 1.402533989 & 2.0132685 & 2.252333 & 0.435450774 & 0.605902615 \\
\hline Gouxiheshidi & 4.079206322 & 4.1594578 & 3.728884 & 0.019673307 & -0.08588002 \\
\hline Guangwushan & 3.669389547 & 4.0787234 & 3.7616593 & 0.111553665 & 0.025145805 \\
\hline Guhaian (Tianjing) & 1.329830276 & 1.5704211 & 1.5878316 & 0.180918444 & 0.194010716 \\
\hline Guniujiang & 3.57206942 & 4.3096911 & 3.9605627 & 0.206497017 & 0.108758603 \\
\hline Guposhanshuiyuanlin & 4.035366563 & 4.9541409 & 4.7622043 & 0.227680515 & 0.180116905 \\
\hline Haiyangshanshuiyuanlin & 4.123817147 & 4.810177 & 4.6425934 & 0.166437994 & 0.125800014 \\
\hline Haizishan & 0.736253343 & 1.118952 & 1.6183143 & 0.519792081 & 1.198040003 \\
\hline Hanasi & 0.492735606 & 0.7246338 & 1.4470392 & 0.470634132 & 1.936745757 \\
\hline Hanma & 0.096370639 & 0.1567511 & 0.3420536 & 0.626544159 & 2.549354903 \\
\hline Heilihe & 0.666124926 & 0.9969191 & 1.3844194 & 0.496594799 & 1.078317964 \\
\hline Heilonggong & 0.320917678 & 0.5791164 & 0.7352973 & 0.804563724 & 1.291233392 \\
\hline Heishantou & 0.113505814 & 0.2222014 & 0.5145099 & 0.957621307 & 3.532894676 \\
\hline Heishuihe & 3.047325448 & 3.6869272 & 3.8800535 & 0.209889545 & 0.273265218 \\
\hline Helanshan (Ningxia) & 1.422396867 & 2.0784923 & 2.2252012 & 0.46126046 & 0.56440249 \\
\hline Helanshanshuiyuanhanyanglin (Neimeng) & 1.299201368 & 1.8780089 & 2.0024912 & 0.445510254 & 0.541324732 \\
\hline Hepu rugen & 5.011440922 & 5.0482994 & 5.1063827 & 0.007354866 & 0.018945006 \\
\hline Hesigechuor & 0.184012734 & 0.4104674 & 0.6653623 & 1.230646712 & 2.615849216 \\
\hline Hongba & 1.514917419 & 2.2236418 & 2.3874644 & 0.467830373 & 0.575969997 \\
\hline Honghe & 0.375266436 & 0.6961311 & 1.0984756 & 0.855031607 & 1.927188511 \\
\hline Honghua'er'jichangzhangzisonglin & 0.150298859 & 0.2506426 & 0.5995992 & 0.667628096 & 2.989379587 \\
\hline Honghushidi & 3.714843677 & 3.9892489 & 3.8569874 & 0.073867233 & 0.038263716 \\
\hline Houhe & 3.423165934 & 3.955298 & 4.0340362 & 0.155450269 & 0.178451842 \\
\hline Huagaoxi & 4.045582902 & 4.2214755 & 3.884153 & 0.04347769 & -0.039902755 \\
\hline Huang Long & 1.468625458 & 2.3589348 & 2.7255073 & 0.606219467 & 0.855821908 \\
\hline Huang Shan & 3.581699243 & 4.4166519 & 4.0191771 & 0.233116351 & 0.122142544 \\
\hline Huanghegudaoshidi & 1.719022713 & 1.9421119 & 1.8753494 & 0.129776754 & 0.09093928 \\
\hline Huanghesanjiaozhou & 1.692432243 & 2.1877714 & 1.9383856 & 0.29267887 & 0.145325379 \\
\hline Huangheshidi & 2.604529637 & 2.5749698 & 2.3813474 & -0.011349396 & -0.085690035 \\
\hline Huangheshouqu & 1.198754052 & 2.4242601 & 2.8997985 & 1.022316501 & 1.419010384 \\
\hline Huanglianshan & 5.200654594 & 5.466738 & 5.847181 & 0.051163445 & 0.124316352 \\
\hline Huanglianshanshuiyuanlin & 4.87267502 & 5.0452256 & 4.8449926 & 0.035411879 & -0.005681155 \\
\hline Huaping & 3.957146575 & 4.660721 & 4.7623428 & 0.177798424 & 0.203478999 \\
\hline Huashuichongshuiyuanlin & 4.240136494 & 5.0120098 & 4.8664545 & 0.182039731 & 0.147711756 \\
\hline Huihe & 0.119540898 & 0.236545 & 0.5829069 & 0.978778844 & 3.87621316 \\
\hline Humahe & 0.159231741 & 0.3347174 & 0.7894514 & 1.102077123 & 3.957877086 \\
\hline Huochengsizhualugui & 2.65524078 & 2.8764318 & 2.7659642 & 0.083303564 & 0.041699955 \\
\hline Huzhong & 0.103698918 & 0.1655946 & 0.3709349 & 0.596878764 & 2.577037323 \\
\hline Jianfengling & 6.427512043 & 6.4288437 & 6.0850099 & 0.000207181 & -0.053286892 \\
\hline Jiangcun & 1.321870747 & 1.5581834 & 1.9513201 & 0.178771377 & 0.476180712 \\
\hline Jiangxiwuyishan & 4.16857114 & 4.5717325 & 4.9945192 & 0.096714521 & 0.198136971 \\
\hline Jiaqiaolingshuiyuanlin & 4.251732296 & 4.7277762 & 4.5093215 & 0.111964694 & 0.06058453 \\
\hline Jiaxi & 6.456783457 & 6.5712797 & 6.3103195 & 0.017732706 & -0.022683734 \\
\hline
\end{tabular}




\begin{tabular}{|c|c|c|c|c|c|}
\hline Name & Current & Low & High & Low-change & High-change \\
\hline Jiejingkou & 0.3406554 & 0.6530771 & 0.9676376 & 0.91711947 & 1.840517426 \\
\hline Jin Zhai Gou & 1.58088584 & 2.5481558 & 2.8900921 & 0.611853137 & 0.828147249 \\
\hline Jinfoshan & 3.783649179 & 4.0667182 & 3.8758498 & 0.07481376 & 0.024368174 \\
\hline Jingangtai & 3.317290761 & 3.469444 & 3.4888029 & 0.045866718 & 0.051702474 \\
\hline Jingbohu & 0.551775952 & 0.9941344 & 1.2141727 & 0.801699397 & 1.200481365 \\
\hline Jinggangshan & 3.972931325 & 4.6766994 & 4.4803111 & 0.17714076 & 0.127709173 \\
\hline Jinpingfenshuiling & 4.499785327 & 4.7277904 & 5.0365844 & 0.050670211 & 0.119294374 \\
\hline Jintangkongyu & 1.921151073 & 2.5756459 & 3.0938951 & 0.34067848 & 0.610438213 \\
\hline Jinyunshan & 4.457848275 & 4.4195618 & 3.9280611 & -0.008588555 & -0.118843698 \\
\hline Jinzhongshan & 4.687741682 & 5.1219961 & 4.9311732 & 0.092636166 & 0.05192938 \\
\hline Jiudingshan & 2.62135821 & 3.2398644 & 3.3155459 & 0.235948749 & 0.264819851 \\
\hline Jiugongshan & 3.396543347 & 4.2514869 & 3.9315731 & 0.25170989 & 0.157521839 \\
\hline Jiuwanshanshuiyuanlin & 4.195228936 & 4.5764742 & 4.7234784 & 0.090875914 & 0.125916719 \\
\hline Jiuyishan & 4.087967301 & 4.9634151 & 4.6755687 & 0.214152349 & 0.143739261 \\
\hline Kalamailishan & 1.216526787 & 1.5187629 & 2.0973507 & 0.248441807 & 0.724048104 \\
\hline Kashahu & 1.311950373 & 2.4513161 & 3.0544196 & 0.868451849 & 1.328151783 \\
\hline Keerxin & 0.43003141 & 0.7316846 & 0.8073818 & 0.701467807 & 0.877494949 \\
\hline Kekexili & 0.116443458 & 0.4856354 & 0.664697 & 3.170568346 & 4.708324121 \\
\hline Kenting & 4.650508798 & 3.7180358 & 3.6024545 & -0.200509888 & -0.225363362 \\
\hline Ku'erbin & 0.21556771 & 0.3929574 & 0.6830063 & 0.822895461 & 2.168407272 \\
\hline Labahe & 2.928455529 & 3.5021062 & 3.7542428 & 0.195888469 & 0.281987301 \\
\hline Langcun & 0.829746806 & 1.6189519 & 2.6268773 & 0.951139659 & 2.16587817 \\
\hline Laoshan & 3.502353489 & 4.0273222 & 3.6781209 & 0.14989027 & 0.050185514 \\
\hline Laoshan & 2.47116014 & 2.9672197 & 2.5445171 & 0.200739544 & 0.029685231 \\
\hline Laotudingzi & 0.520627921 & 0.8766302 & 0.9796121 & 0.683794058 & 0.881597318 \\
\hline Laoxiancheng & 2.801765329 & 3.3794668 & 3.2922669 & 0.206191955 & 0.175068756 \\
\hline Leigongshan & 3.617425677 & 4.1193028 & 4.4312704 & 0.138738752 & 0.224978976 \\
\hline Leiwuqi & 0.717355376 & 1.4067066 & 2.5502438 & 0.960961954 & 2.555063341 \\
\hline Leizhou Rare Marine Life & 0.279471662 & 0.2804547 & 0.2664467 & 0.003517487 & -0.046605663 \\
\hline Lian Huan $\mathrm{Hu}$ & 0.366932889 & 0.5407905 & 0.811421 & 0.473813104 & 1.211360781 \\
\hline Liancheng & 1.26867781 & 2.3219657 & 2.8948438 & 0.830224886 & 1.281780116 \\
\hline Liangucheng & 0.996566208 & 1.5130357 & 2.0309251 & 0.518249051 & 1.037922903 \\
\hline Liangyeshan & 4.473078984 & 5.086663 & 5.5386353 & 0.137172632 & 0.238215404 \\
\hline Lingnan & 3.765201678 & 4.5642651 & 4.0691275 & 0.212223273 & 0.080719666 \\
\hline Lingqiuqingtun & 1.463160215 & 1.807377 & 1.4957921 & 0.235255703 & 0.022302332 \\
\hline Lishan & 2.383144667 & 2.6577278 & 2.4785096 & 0.115218827 & 0.040016426 \\
\hline Liupanshan & 2.247728102 & 2.9802779 & 3.1895395 & 0.325906767 & 0.419005927 \\
\hline Longbao & 0.539827103 & 1.0910366 & 2.1039936 & 1.021085258 & 2.897532355 \\
\hline Longganhu & 3.629671022 & 4.263526 & 3.5162698 & 0.174631523 & -0.031242838 \\
\hline Longwan & 0.38756117 & 0.6466648 & 0.8194125 & 0.668548993 & 1.114279147 \\
\hline Longxihongkou & 3.214561441 & 3.6995559 & 3.7267688 & 0.150874223 & 0.159339732 \\
\hline Luanheyuancaodi & 4.867275133 & 4.3397563 & 4.2873983 & -0.10838073 & -0.119137878 \\
\hline Luoshan & 1.825088565 & 2.4842113 & 2.6502165 & 0.361145617 & 0.452102956 \\
\hline Luoxu & 0.627191882 & 1.2530207 & 2.0602264 & 0.997826719 & 2.284842261 \\
\hline Lushan & 3.933653669 & 4.6004531 & 4.2564231 & 0.169511474 & 0.082053342 \\
\hline Lushidani & 3.064114253 & 3.158907 & 2.8135776 & 0.030936427 & -0.081764788 \\
\hline Luyashan & 0.950415949 & 1.5357447 & 1.7078583 & 0.615865876 & 0.796958797 \\
\hline Mabiandafengding & 3.150848417 & 3.7765117 & 3.7137125 & 0.198569782 & 0.178638896 \\
\hline Mangkang & 1.508791551 & 2.2683431 & 2.3152967 & 0.503417154 & 0.534537159 \\
\hline Mangshan & 3.956484796 & 4.7755036 & 5.0121092 & 0.207006686 & 0.266808659 \\
\hline Manzetangshidi & 1.108426009 & 1.9325509 & 2.9870393 & 0.74350916 & 1.694847717 \\
\hline Maoershan & 3.717741689 & 4.5665343 & 4.7695168 & 0.228308657 & 0.28290699 \\
\hline Maoershan & 0.420672612 & 0.7190534 & 0.9726003 & 0.709294543 & 1.312012411 \\
\hline Maojieniaolei & 4.799302307 & 5.2228477 & 5.0493304 & 0.088251451 & 0.052096758 \\
\hline
\end{tabular}




\begin{tabular}{|c|c|c|c|c|c|}
\hline Name & Current & Low & High & Low-change & High-change \\
\hline Maolan & 4.27280106 & 4.5967033 & 4.6510033 & 0.075805598 & 0.088513889 \\
\hline Maoshan & 0.192927715 & 0.4251202 & 0.7912416 & 1.203520629 & 3.101233459 \\
\hline Mayangheheiyehou & 3.865217812 & 4.1581757 & 3.8065134 & 0.075793371 & -0.015187866 \\
\hline Meigudafengding & 2.985776711 & 3.6786022 & 3.6260661 & 0.232041963 & 0.214446508 \\
\hline Meihuashan & 4.669146936 & 5.2814537 & 5.9372162 & 0.131138894 & 0.271584784 \\
\hline Mengda & 1.552720746 & 2.5167115 & 3.0781737 & 0.620839746 & 0.982438702 \\
\hline Mianshan & 2.087279858 & 2.2833927 & 2.1241097 & 0.09395618 & 0.017644899 \\
\hline Micangshan & 3.62645716 & 3.8435796 & 3.589351 & 0.059871779 & -0.010232069 \\
\hline Minjiangbai & 1.804775928 & 2.4589164 & 3.4289343 & 0.362449688 & 0.899922448 \\
\hline Momoge & 0.391668358 & 0.580151 & 0.8334726 & 0.481230199 & 1.12800596 \\
\hline Mudanfeng & 0.51741769 & 0.9507688 & 1.3357585 & 0.837526661 & 1.581586455 \\
\hline Mulinzi & 3.422753301 & 3.9917032 & 3.9998137 & 0.166225798 & 0.168595382 \\
\hline Mulun & 4.354657004 & 4.6045431 & 4.647664 & 0.057383646 & 0.067285895 \\
\hline Mupinghu & 3.800973992 & 4.3609185 & 4.0455318 & 0.147316059 & 0.064340826 \\
\hline Namusilai & 0.870281819 & 1.2314424 & 1.1692505 & 0.414992676 & 0.343530882 \\
\hline Nandongtihu Shidi and Shuiqin & 3.802469437 & 4.388544 & 3.971799 & 0.154129987 & 0.044531472 \\
\hline Nangunhe & 4.957876728 & 5.4808349 & 6.0436073 & 0.105480269 & 0.218991038 \\
\hline Nanling & 3.970448966 & 4.7750611 & 5.0630911 & 0.202650164 & 0.275193597 \\
\hline Nansihu & 2.302205243 & 2.6691182 & 2.3885047 & 0.159374564 & 0.037485562 \\
\hline Nanwenghe & 0.146800332 & 0.2856544 & 0.7191587 & 0.945870259 & 3.898890147 \\
\hline Nanyangkonglongdanhuashiqaun & 3.083725701 & 2.9745135 & 2.6665973 & -0.035415666 & -0.135267673 \\
\hline Nanyuehengshan & 4.19229214 & 4.9305377 & 4.8986686 & 0.176095924 & 0.168494093 \\
\hline Nazoushuiyuanlin & 4.95240428 & 5.2613022 & 5.0417035 & 0.062373325 & 0.018031488 \\
\hline Neixiangbaotianman & 2.87574233 & 2.9890161 & 2.6838037 & 0.039389402 & -0.066744029 \\
\hline Nianlong & 0.673981487 & 1.113588 & 2.3452111 & 0.652253098 & 2.479637268 \\
\hline Nonggang & 4.942850266 & 4.7402721 & 4.5984173 & -0.040984079 & -0.069683067 \\
\hline Panzhihuasutiesutie & 4.376400448 & 4.6101161 & 4.6956361 & 0.053403626 & 0.072944799 \\
\hline Pishangou & 0.743091317 & 1.0304883 & 1.0897775 & 0.386758634 & 0.466545867 \\
\hline Poyanghulijiyuchanluanchang & 3.683235151 & 4.2913702 & 3.6359704 & 0.165108939 & -0.012832401 \\
\hline Qianfoshan & 3.456355012 & 3.8333341 & 3.6747835 & 0.109068393 & 0.063196196 \\
\hline Qiangtang & 0.142320064 & 0.3363909 & 0.5623604 & 1.363622462 & 2.951378212 \\
\hline Qianjiadongshuiyuanlin & 3.99580901 & 4.9413833 & 4.8074861 & 0.236641513 & 0.203132104 \\
\hline Qilianshan & 0.585662053 & 1.2939186 & 1.9769024 & 1.20932634 & 2.375500239 \\
\hline Qinghaihuniaodao & 0.620402936 & 1.775535 & 2.3756885 & 1.861906185 & 2.829267017 \\
\hline Qingliangfeng & 3.638672235 & 4.2046866 & 3.8935602 & 0.155555194 & 0.070049718 \\
\hline Qingshitanshuiyuanlin & 4.086825363 & 4.7388727 & 4.7408752 & 0.159548618 & 0.160038607 \\
\hline Qixinghe & 0.496490676 & 0.8872769 & 1.208391 & 0.787096803 & 1.433864438 \\
\hline Qixinglazi & 0.377813653 & 0.7623187 & 1.231765 & 1.017710832 & 2.260244806 \\
\hline Queershan & 1.034280414 & 2.3431316 & 2.9973743 & 1.265470339 & 1.898028677 \\
\hline Quomolangma & 0.402532064 & 0.6339384 & 0.9115877 & 0.574876778 & 1.264633756 \\
\hline Ribaxueshan & 0.91896993 & 1.7143432 & 2.4622932 & 0.865505218 & 1.679405625 \\
\hline Riganqiaoshidi & 1.395896878 & 2.8567253 & 3.0943032 & 1.046516003 & 1.216713318 \\
\hline Rongchengtianee & 2.400741937 & 0.9815751 & 0.8954855 & -0.591136771 & -0.626996352 \\
\hline Ruoergaishidi & 1.191480653 & 2.7467948 & 3.0479123 & 1.305362486 & 1.558087949 \\
\hline Sandagu & 1.101322859 & 1.9048686 & 2.5908522 & 0.729618689 & 1.352491078 \\
\hline Sanjiang & 0.392006461 & 0.7188821 & 1.097434 & 0.833852682 & 1.799530388 \\
\hline Sanjiangyuan & 0.409948785 & 0.8813389 & 1.4625438 & 1.149875624 & 2.567625649 \\
\hline Sanpihushuiyuanlin & 4.413829766 & 4.6808017 & 4.380299 & 0.060485326 & -0.007596751 \\
\hline Selincuoheijinghe & 0.242026402 & 0.6159431 & 1.2225865 & 1.54494177 & 4.051459221 \\
\hline Shankou hongshulin & 4.648508413 & 4.694658 & 4.5818393 & 0.009927827 & -0.014342044 \\
\hline Shapotou & 1.767804306 & 2.3346807 & 2.5180899 & 0.320666938 & 0.424416657 \\
\hline Shedao-laotieshan & 2.35352009 & 3.0046636 & 2.5923355 & 0.276667921 & 0.101471583 \\
\hline Shei-Pa & 5.529632737 & 5.8106414 & 5.9472897 & 0.050818685 & 0.075530688 \\
\hline Shenmuchoubai & 1.572859382 & 2.0394837 & 1.9446701 & 0.296672623 & 0.236391582 \\
\hline
\end{tabular}




\begin{tabular}{|c|c|c|c|c|c|}
\hline Name & Current & Low & High & Low-change & High-change \\
\hline Shennongjia & 3.03960801 & 3.3772771 & 3.455241 & 0.111089683 & 0.13673901 \\
\hline Shimenhupingshan & 3.522257613 & 4.0369354 & 4.0200765 & 0.146121563 & 0.141335172 \\
\hline Shimentai & 4.34055815 & 4.9686015 & 5.2527353 & 0.144691841 & 0.21015204 \\
\hline Shiwandashanshuiyuanlian & 5.361982368 & 5.2986107 & 5.2353774 & -0.011818701 & -0.023611597 \\
\hline Shouchengshuiyuanlin & 4.136012421 & 4.6743513 & 4.5535564 & 0.130158913 & 0.10095327 \\
\hline Shoulushan & 1.329549648 & 2.2403738 & 2.7076785 & 0.685062159 & 1.036538089 \\
\hline Shuangtaihekou & 1.280107139 & 1.3249515 & 1.5153521 & 0.035031725 & 0.183769744 \\
\hline Shuguang & 0.495156359 & 0.8889053 & 1.3803384 & 0.79520122 & 1.78768186 \\
\hline Simianshan & 4.342941694 & 4.2967751 & 3.8913278 & -0.010630259 & -0.103988017 \\
\hline Songfengshan & 0.311807626 & 0.5730393 & 0.739885 & 0.837797578 & 1.372889366 \\
\hline Songhuaba & 4.136122479 & 4.6244788 & 5.0062412 & 0.118071049 & 0.210370637 \\
\hline Songhuajiangsanhu & 0.487841987 & 0.7779641 & 0.8678869 & 0.59470509 & 0.779032808 \\
\hline Suoxiyu & 3.744563228 & 4.0814605 & 3.9500149 & 0.089969711 & 0.054866659 \\
\hline Susu & 0.427362245 & 0.7864597 & 1.1640926 & 0.840264809 & 1.723901359 \\
\hline Tachengyebadanxing & 1.113086442 & 1.5539888 & 2.244644 & 0.396107922 & 1.016594503 \\
\hline Taibaishan & 2.190025012 & 2.8556487 & 2.9680267 & 0.303934286 & 0.355247855 \\
\hline Taitong - kongdongshan & 2.479497096 & 3.1889538 & 3.2369633 & 0.286129274 & 0.30549187 \\
\hline Talimuhuyanglin (Tarim) & 0.731850107 & 0.7827091 & 1.4347354 & 0.069493729 & 0.960422478 \\
\hline Tangjiahe & 3.26731949 & 3.9000298 & 3.6454454 & 0.19364813 & 0.115729702 \\
\hline Taoyuandong & 4.010578083 & 4.65248 & 4.5882173 & 0.160052218 & 0.144028917 \\
\hline Taroko & 6.40065087 & 6.4569357 & 6.3754622 & 0.00879361 & -0.003935329 \\
\hline Tashikuerganyeshengdongwu & 0.3747755574 & 0.4841934 & 1.0601476 & 0.291955596 & 1.828753189 \\
\hline Tawushan & 6.449766139 & 6.5764015 & 6.6226019 & 0.019634101 & 0.026797214 \\
\hline Tianchi (Xinjiang) & 0.413640792 & 0.8270696 & 1.8216088 & 0.999487517 & 3.403842259 \\
\hline Tianma & 3.260532899 & 3.7689337 & 3.9094255 & 0.155925677 & 0.199014278 \\
\hline Tiebu & 1.49233669 & 2.6581784 & 3.1729697 & 0.781218955 & 1.126175495 \\
\hline Tiexi & 0.757873908 & 1.1927998 & 1.6746278 & 0.573876324 & 1.209639074 \\
\hline Tongbiguan & 4.695141012 & 5.708225 & 5.9362822 & 0.215772857 & 0.264345881 \\
\hline Touersantan & 3.485723924 & 3.9518337 & 3.5432415 & 0.133719648 & 0.016500898 \\
\hline Tunhuangxihu & 0.78660997 & 0.8856022 & 1.2197254 & 0.125846651 & 0.550610145 \\
\hline Tuomuerfeng & 0.247492323 & 0.4853855 & 0.6563681 & 0.961214369 & 1.652074586 \\
\hline Wahuishan & 1.008375306 & 1.3062069 & 1.6669644 & 0.295357881 & 0.653119022 \\
\hline Wanglang & 1.966656941 & 2.913366 & 3.0888863 & 0.481379868 & 0.060246567 \\
\hline Wawushan & 3.393578096 & 3.9592295 & 3.9729427 & 0.16668289 & 0.170723816 \\
\hline Weiyuanjiang & 5.296218996 & 5.3039563 & 5.541466 & 0.001460911 & 0.046306054 \\
\hline WenchuanCaopo & 2.482182373 & 3.0895488 & 3.3849365 & 0.244690492 & 0.363693714 \\
\hline Wenlanjiang & 5.512020513 & 5.3077275 & 5.3905429 & -0.037063181 & -0.022038672 \\
\hline Wenshanlaojunshan & 4.625134114 & 5.0914454 & 5.5123206 & 0.100821138 & 0.191818543 \\
\hline Wolong & 2.226933152 & 2.9311619 & 3.341406 & 0.316232549 & 0.500451864 \\
\hline Wu Ling Yuan & 3.706937481 & 4.1440955 & 4.016746 & 0.117929698 & 0.083575329 \\
\hline Wudalianchihuoshan & 0.192568797 & 0.4054511 & 0.8224395 & 1.105487007 & 3.270886628 \\
\hline Wujiao & 2.506918055 & 3.3708793 & 3.3205089 & 0.344630828 & 0.324538269 \\
\hline Wulatelenglenglin--mengguyelv & 0.552223979 & 0.8240096 & 1.1897453 & 0.492165555 & 1.154461496 \\
\hline Wuliangshan & 4.276610942 & 4.9705823 & 5.6408029 & 0.162271333 & 0.318989026 \\
\hline Wuliangsuhainiaolei & 0.642323075 & 1.0380845 & 1.0480873 & 0.616140756 & 0.631713605 \\
\hline Wulingshan & 0.785673619 & 1.0396885 & 1.2165839 & 0.3233084 & 0.548459654 \\
\hline Wulushan & 2.115315374 & 2.6604441 & 2.54036 & 0.257705651 & 0.200936764 \\
\hline Wuyishan & 4.249849161 & 4.6599941 & 5.1109583 & 0.096508117 & 0.202621106 \\
\hline Wuzhishan & 6.686374936 & 6.7594269 & 6.6454659 & 0.010925496 & -0.006118268 \\
\hline Xianghai & 0.405432707 & 0.7253346 & 0.817071 & 0.789038199 & 1.015306081 \\
\hline Xiangshan & 3.268353297 & 3.8189908 & 3.7705003 & 0.168475514 & 0.153639144 \\
\hline Xiangtoushan & 5.40113347 & 5.9018235 & 5.6097032 & 0.092700918 & 0.038615919 \\
\hline Xianrendong & 1.406685222 & 2.025562 & 1.9842726 & 0.439953991 & 0.410601725 \\
\hline Xiaohe & 3.564841683 & 3.9950627 & 4.0655956 & 0.120684467 & 0.14047017 \\
\hline
\end{tabular}




\begin{tabular}{|c|c|c|c|c|c|}
\hline Name & Current & Low & High & Low-change & High-change \\
\hline Xiaohegou & 2.628934089 & 3.4445591 & 3.3231073 & 0.310249319 & 0.264051204 \\
\hline Xiaosuganhu & 1.02197917 & 1.3578324 & 1.6552772 & 0.328630211 & 0.619678021 \\
\hline Xiaowutaishan & 0.859756071 & 1.2860287 & 1.2326404 & 0.495806477 & 0.433709446 \\
\hline Xiaoxi & 3.597079523 & 3.9896132 & 4.0923405 & 0.10912566 & 0.137684189 \\
\hline Xiaozhaizigou & 2.561513663 & 3.1436491 & 3.2286073 & 0.227262281 & 0.260429467 \\
\hline Xidamingshanshuiyuanlin & 4.953416169 & 4.7663636 & 4.8259502 & -0.037762337 & -0.025732942 \\
\hline Xi'e'erduosi & 1.280985413 & 1.8391057 & 1.8368926 & 0.435696052 & 0.433968398 \\
\hline Xilinguolecaoyuan & 0.24001529 & 0.5176482 & 0.7557911 & 1.156730098 & 2.14892897 \\
\hline Xingdoushan & 3.624776709 & 4.1074179 & 3.969299 & 0.133150599 & 0.095046487 \\
\hline Xingkaihu & 0.801902821 & 1.2059164 & 1.7160298 & 0.503818628 & 1.139947329 \\
\hline Xinglongshan & 1.592556376 & 2.5735305 & 3.1120161 & 0.615974504 & 0.954101058 \\
\hline Xinjiangluobupoyeshuangfengtuo & 0.377652057 & 0.6351586 & 1.0385473 & 0.681861884 & 1.750010971 \\
\hline Xinningshunhuangshan & 3.985194504 & 4.6291497 & 4.7515863 & 0.161586893 & 0.192309759 \\
\hline Xionglongxi & 1.126909278 & 1.9786615 & 2.5893394 & 0.755830339 & 1.297735453 \\
\hline Xishuangbanna & 5.576098026 & 5.8063043 & 5.7907511 & 0.041284474 & 0.038495212 \\
\hline Xishuangbanna & 5.624244814 & 5.88671 & 5.8572166 & 0.046666743 & 0.041422768 \\
\hline Xishuizhongyaredaisenlin & 3.929326843 & 4.1611994 & 3.882315 & 0.059010758 & -0.01196435 \\
\hline Xitianshan & 1.282375399 & 1.5494784 & 1.6335789 & 0.208287683 & 0.273869493 \\
\hline Xuebaoding & 2.815380854 & 3.4853574 & 3.4141119 & 0.237970129 & 0.212664317 \\
\hline Xunbielahe & 0.229326621 & 0.4875641 & 0.8174838 & 1.126068478 & 2.564713928 \\
\hline Yading & 1.381329549 & 1.6796899 & 1.9996408 & 0.215995054 & 0.447620375 \\
\hline Yalujiangbinhaishidi & 1.779385149 & 2.3025369 & 2.1080035 & 0.294007035 & 0.184680844 \\
\hline Yaluzangbudaxiagu & 2.811536007 & 3.53505 & 3.8080543 & 0.257337623 & 0.3544391 \\
\hline Yaluzangbujiangzhongyouheguoheijinghe & 0.536832254 & 1.0595916 & 1.5541322 & 0.973785279 & 1.895005262 \\
\hline Yanboyezeshan & 1.158267795 & 2.2741909 & 2.973453 & 0.963441365 & 1.567155033 \\
\hline Yancheng & 2.570085802 & 2.3541128 & 2.3982959 & -0.084033382 & -0.066842088 \\
\hline Yangchengmanghemihou & 2.564979596 & 2.6777729 & 2.3767916 & 0.043974347 & -0.073368223 \\
\hline Yangxianzhuhuan & 3.636850474 & 3.7548798 & 3.3665618 & 0.03245372 & -0.074319435 \\
\hline Yangzie & 3.604495881 & 4.0008207 & 3.5960218 & 0.109952912 & -0.002350975 \\
\hline Yihuanghuananhu & 3.873180847 & 4.3230026 & 4.2315213 & 0.116137555 & 0.092518389 \\
\hline Yindingshanshuiyuanlin & 4.077412271 & 4.8908244 & 4.6513785 & 0.199492245 & 0.140767279 \\
\hline Yiwulushan & 1.141283391 & 1.3711778 & 1.5506742 & 0.20143499 & 0.358710915 \\
\hline Yongzhoudupangling & 4.042135196 & 4.9242673 & 4.744988 & 0.218234191 & 0.173881568 \\
\hline Youyi & 0.94899932 & 1.8821107 & 2.7550495 & 0.983258218 & 1.903110089 \\
\hline Yuanbaoshanshuiyuanlin & 3.949066789 & 4.60341 & 4.7112504 & 0.165695656 & 0.193003474 \\
\hline Yuanshan & 1.966113109 & 2.4518978 & 2.0421601 & 0.24707871 & 0.038678848 \\
\hline Yueyahu & 0.592437574 & 0.9492332 & 1.4326278 & 0.602250164 & 1.418191997 \\
\hline Yuke & 0.952112713 & 1.8103647 & 2.7074516 & 0.901418472 & 1.843625091 \\
\hline Yulongxueshan & 2.427936926 & 2.8823653 & 3.1887478 & 0.187166466 & 0.313356935 \\
\hline Yunchengtianee & 2.721900784 & 2.9060026 & 2.5767111 & 0.067637225 & -0.053341284 \\
\hline Yunling & 3.607845269 & 4.1090513 & 4.4952158 & 0.138921155 & 0.245955817 \\
\hline Yunnandaweishan & 5.732517823 & 5.7859962 & 5.9304935 & 0.009328951 & 0.034535554 \\
\hline Yunwushancaoyuan & 2.126109799 & 2.7576579 & 3.0100536 & 0.297043973 & 0.415756421 \\
\hline Yushan & 5.693405357 & 5.9928932 & 6.0700757 & 0.052602586 & 0.066159059 \\
\hline Zhagashenshan & 1.11401156 & 1.8823403 & 2.5351139 & 0.689695482 & 1.275662113 \\
\hline Zhalong & 0.288557936 & 0.519417 & 0.8907593 & 0.800044065 & 2.086933987 \\
\hline Zhangjiajiedani & 3.746332725 & 4.1066225 & 3.9822749 & 0.096171323 & 0.062979504 \\
\hline Zhangmukouan & 1.299713281 & 1.4389909 & 1.970977 & 0.107160265 & 0.516470616 \\
\hline Zhouzhijinsihou & 3.039861443 & 3.4981733 & 3.3203029 & 0.150767351 & 0.092254684 \\
\hline Zhuchanggou & 1.490779594 & 2.1443633 & 3.1438463 & 0.438417395 & 1.108860567 \\
\hline Zhujiangkouzhonghuabaijitun & 0.274393703 & 0.0371043 & 0.0371043 & -0.864777145 & -0.864777145 \\
\hline Zhujiangyuantou & 4.046219123 & 4.5566399 & 4.8763739 & 0.126147587 & 0.205168023 \\
\hline Zhumulangmafeng & 0.346179922 & 0.55216 & 0.9369674 & 0.595008737 & 1.706590823 \\
\hline Ziyunwanfengshan & 3.674821498 & 4.3552625 & 4.7189632 & 0.185163008 & 0.284133992 \\
\hline
\end{tabular}

